Styrvold, M., Knotten, V., and Lædre, O. (2019). "Planning the BIM Process in AEC Projects." In: Proc. $27^{\text {th }}$ Annual Conference of the International. Group for Lean Construction (IGLC), Pasquire C. and Hamzeh F.R. (ed.), Dublin, Ireland, pp. 527-538. DOI: https://doi.org/10.24928/2019/0208. Available at: <www.iglc.net>.

\title{
PLANNING THE BIM PROCESS IN AEC PROJECTS
}

\author{
Marie Styrvold ${ }^{1}$, Vegard Knotten², and Ola Lædre ${ }^{3}$
}

\begin{abstract}
The architectural, engineering and construction industry (AEC Industry) needs to focus on the early design phases. The use of Lean Design Management and Building Information Model (BIM) can be used together for reducing uncertainty and improve communication. BIM requires new working methods, and the use of Level of Development (LoD) or model maturity is proposed as a key element to align the challenges in the design phase and to generate an enhanced design process.

This paper addresses these challenges and aim to answer three research questions. RQ1: What approaches to model maturity are used or attempted in the Norwegian AEC industry? RQ2: What experiences do the actors of the AEC industry have towards the use of model maturity? RQ3: How can model maturity be implemented in an AEC project?

The research method is based on a literature study and a study based on semi-structured interviews. This paper presents an analysis of the interviewees regarding the experiences the industry has with the use of model maturity. There is proposed a framework based on the results, about how to implement model maturity in construction projects. The framework is generic and can be adapted to different construction projects independent of contract form.
\end{abstract}

\section{KEYWORDS}

BIM, model maturity, design management, lean design, collaborative planning

\section{INTRODUCTION}

Research has highlighted the importance of the early design phase to reduce uncertainty, improve quality and consequently the overall performance in construction projects (El Reifi et al. 2013). The design process is important for creating successful construction projects (Bølviken et al. 2010).

Many contractors have successfully implemented Lean Construction for reducing waste in the production phase to improve productivity (Emmitt et al. 2004). This opens for using Lean Design Management in the early design phases (El. Reifi and Emmitt 2013). There

1 MSc Student, Department of civil and environmental engineering, The Norwegian University of Science and Technology (NTNU), 7491 Trondheim, Norway, Mobile +4748126153, marie.styrvold@ gmail.com

2 Associate professor II, PhD, Department of Architecture and Planning, NTNU. Head of BIM and Design management development (Veidekke), vegard.knotten@ veidekke.no

3 Professor, dr. ing, Department of civil and environmental engineering, The Norwegian University of Science and Technology (NTNU), ola.laedre@ntnu.no 
is proven to be synergy effects between the use of Lean and BIM (Sacks et al. 2010a). The increased use of Building Information Model (BIM) requires a different design management strategy than a traditional 2D - CAD process (Abou-Ibrahim and Hamzeh 2017). Level of Development (LoD) was created for facilitating the use of BIM as a work process, to formalize the development of BIM models and authorize their possible uses (BIMForum 2018). The expected benefits of using LoD are improved productivity and efficiency in communication - and enhanced development of the model (Hooper 2015).

Due to the current usage of the LoD concept, many researchers and practitioners have raised several concerns about the LoD concept, due to how it is currently understood and used (Abou-Ibrahim and Hamzeh 2016). The Norwegian AEC Industry have made their own LoD framework, called Model Maturity Index (MMI). This framework aims to reduce the uncertainty around LoD and focus on improving the design processes (Fløisbonn et al. 2018). This framework is created as a collaborative effort between architects, consultants and contractors, and is supposed to be an agreed framework for all actors in the AEC Industry.

Achievements of the mentioned benefits could lead to an improved design process through improved utilization of BIM, and thus increased productivity. The literature points out the advantages of using BIM together with LoD. However, the planning of BIM process in the AEC industry with the use of LoD and Lean needs more attention. Therefore, this study will investigate the following research questions:

- RQ1: What approaches to model maturity are used or attempted in the Norwegian AEC industry?

- RQ2: What experiences do the actors of the AEC industry have towards the use of model maturity?

- RQ3: How can model maturity be implemented in an AEC project?

\section{METHODICAL APPROACH}

This study is divided into two parts, a literature study and qualitative study. The literature study aims to answer RQ1. RQ2 and RQ3 is answered by using the findings from the qualitative study supported with theory from the literature study.

The literature study was conducted by performing a scoping study, based on five steps made by Arksey and O'Malley (2005). Step 1 was to identify the research questions as presented in the introduction. Step 2 was to identify relevant studies. This was performed through systematic searches in digital databases. There was used different search words and combinations, that had relevance for the research questions. This search results were narrowed down by sorting out articles that wasn't based on the AEC Industry practice. In step 3 the remaining literature was evaluated, the evaluation was based on criteria regarding credibility, objectivity, accuracy and relevance of the article's topic. Furthermore, the remaining articles after the evaluation was used for performing snowballing. Snowballing uses the relevant literature to find more literature, by using the reference list in the article and by identify which articles that has used the article as a reference (Wohlin 2014). Articles that were found through snowballing was evaluated the same way as articles found 
in the scoping study. The next steps were charting the data, collecting, summarizing and reporting the results.

The qualitative study is based on eight performed semi structured in - depth interviews. The interviewees were chosen based on their experience with the use of BIM and LoD. Seven of the interviewees are employed at different constructors. Respectively the interviewees are three BIM managers, three design managers, one VDC responsible, and one production - and process manager. The last interview object is positioned at a consultant and is a design manager at a project where MMI was implemented. The interviews where recorded, transcribed and analysed. To ensure the rigor of qualitative analysis, the data was analysed by using an constant comparative method (CCM) (Corbin and Strauss 2008; Knotten et al. 2017).

\section{THEORETICAL BACKGROUND}

The theoretical background consists of two parts. The first part is about Lean Design management and how to plan the design process. The second part is about the use of model maturity, how it differs from LoD thinking, and how it is used in the Norwegian AEC Industry, answering RQ1.

\section{LEAN DESIGN MANAGEMENT}

There are numerous challenges that must be solved in the construction phase, primarily result of an ineffective communication and poor decision-making in the design phase. This results in some degree of uncertainty in the production phase, and this gives the production team little option but to confront the problem Therefore, Lean philosophy, with its focus on minimizing waste and maximizing value, should be applied as early as possible in the design phases to avoid this problem (Emmitt et al. 2004). Based on a literature review El. Reifi and Emmitt (2013) found that it appears to be four themes related to the reduction of waste and the enhancement of value in Lean design management:

- Briefing and client interaction

- Value and value stream mapping

- Lean culture and assembling the team

- Information flow

To ensure improved project quality, enhanced client relations, and savings in time and cost, it is important that requirements are clearly identified, and information must be well managed through the design process. This will lead to a significant improvement in the decision making (El Reifi et al. 2013). The use of BIM together with Lean Design Management can help the design manager ensure these elements. By using BIM, the content of design work can be visualized in a better way. BIM can improve value adding tasks by reducing the number of design cycles and design errors, which leads to faster, smoother and a more economic process. Further this leads to an increased value realization for the costumer (Arayici et al. 2011). 
The benefits of using BIM are important to quantify, but it is equally important to identify what to include in BIM to achieve the expected value added by using BIM in a construction project (Leite et al. 2011). Due to, increased use of BIM in the construction industry, certain companies have found communication challenging trying to understand the maturity and reliability across disciplines and companies (Garcia et al. 2018). Tauriainen et al. (2016) recommended specifying the instructions and ways of action which are related to BIM in the beginning of the project and suggests that this is done by using LoD.

To improve the planning in design, Svalestuen et al. (2018) proposed three elements that could help the design manager to success: (1) Increased focus on the schedule during the design process, (2) BIM should be used collaboratively as a communication and development tool, and (3) LoD should be used in the planning process. Concluding, Svalestuen et al. (2018) purposed that the AEC industry should use Collaborative Planning in Design (CPD) and adapt the LoD definition to the context of each project. By using LoD as a planning tool, it could be easier to avoid unnecessary iterations, due to the complex tasks and the dependencies in the early phases of the design (Hamzeh et al. 2009).

Knotten (2018) argued for making a design management strategy and separated the design management process into three stages; an assessment-, initialization- and execution stage. In the assessment stage the design manager assesses the project, its objectives, the available resources and preform a self-evaluation. It is important to evaluate the projects purpose and goal in this stage. The initialization stage consists of planning and organizing the project goals, based on the previous assessment. In this stage it is important to address milestones, decision points and necessary output. The execution stage is about performing what's decided in the two earlier stages. In this stage there must be performed an evaluation of the design management process to see if it is developing as expected. If not, steps need to be taken to re-plan and re-organize in order to achieve the project goals.

\section{MODEL MATURITY}

The demand for a metric capable to assess the quality and reliability of the engineering models, has made different markets and regions to create their own guidelines to measure the model maturity (Garcia et al. 2018). Today several metrics are known, such as Level of Model Information (LOI), Level of Detail (LoDt), Level of Development (LoD) and now also Model Maturity Index (MMI). LoD has been criticized for being too advanced and complicated (Nøklebye et al. 2018). This is because LoD only reflects the modelling requirements of an individual object (Abou-Ibrahim and Hamzeh 2017) and therefore it doesn't measure the accuracy of graphical information (Garcia et al. 2018). The big variations in definitions and concepts regarding LoD indicates that the purpose of LoD is not fulfilled (Hooper 2015), and that there is a need for a standardized set of modelling definitions capable to streamline the communication process.

Therefore, the Norwegian AEC industry has created guidelines for how to use MMI as a planning tool for the design process. The MMI is supposed to be a common starting point for the use of model maturity in Norway and the main idea behind the MMI process can be seen in figure 1 (Fløisbonn et al. 2018). 


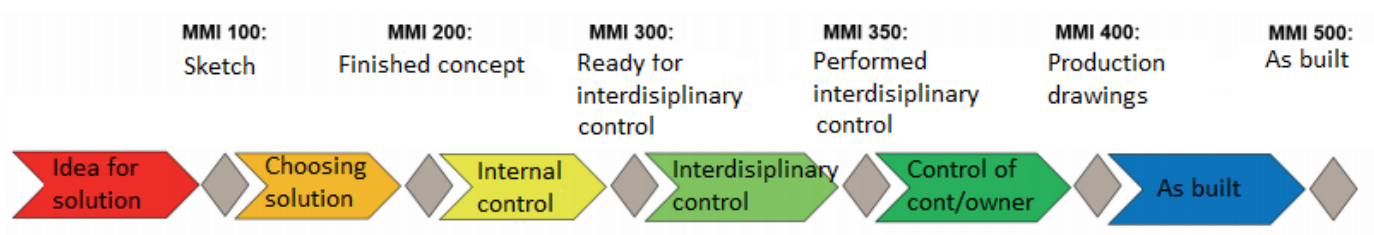

Figure 1: Flow sheet made by Fløisbonn et al. (2018) that should work as a base for a design process using MMI in a Norwegian building project

Today, it is only the contractor Skanska that has taken MMI into use as a business strategy in Norway. Several Lean construction elements are implemented in their approach, such as the combination of Last Planner, BIM and ICE sessions (Fosse et al. 2017). The last element included in their VDC approach is MMI guidelines (Nøklebye et al. 2018).

The approach of using Skanska Norway's MMI strategy in design is: (1) Separate the model into different sections, (2) assign maturity to all geometry, managed by each discipline within each section, (3) coordinate the design team in ICE - sessions utilizing Last Planner for planning and control, (4) create milestones for different sections achieving MMI, and (5) illustrate the achieved MMI milestones by post - it - notes in Last Planner (Nøklebye et al. 2018).

Additionally, metrics for Last Planner (PPC, root cause trends, task completion rate, reliability per trade), BIM clash trends per area according to the MMI plan and ICE session evaluations (session efficiency, team preparations and involvements) is being continuously tracked and visualized on the wall in the Big Room, ensuring transparency and control of the project teams performance (Fosse et al. 2017).

\section{FINDINGS}

The findings section is based on the answers from the eight performed interviews of AEC professionals. The first part deals with the findings regarding which experiences the interviewees have made form using MMI, and this parts answers RQ2. The last part is dealing with what the interviewees thinks about the implementation of MMI in a construction project. This part together with the discussion answers RQ3.

\section{EXPERIENCES}

The interviewees have several positive experiences regarding the use of MMI. The design managers have experienced improved communication between actors in the design process. MMI offers a common language to communicate expectations, dependencies, interfaces and a way to plan the design process. MMI enhances the expectations for the timing for decision making and this makes it easier to understand when the last responsible moment is, for both the client, user, designer and producer.

According to the interviewees, the design team experienced an increase in interdisciplinary communication by using MMI. This makes it easier to create a delivery plan for the design process. A more specific delivery plan for the design team, gives a more structured process which prevent unnecessary iterations to appear. Interviewees from the contractor points out, that a more structured design process makes it easier to coordinate 
with the production team. The effect of this is that the production drawings are finished at the right time, the BIM can therefore be in front of the production and can be used to do calculations and procurement in the production without the production team being uncertain about the reliability of the model.

One interviewee also tried using MMI for performing risk management. By giving the production manager a way to know exactly what's going to change in the model or drawing from one MMI level to the next. This makes it possible to evaluate the risk of performing a task before the production drawings have reached MMI 400.

Some of the interviewed design managers, experienced several challenges when they have started using MMI. First the design managers point out that there is a challenge to know at what MMI level the BIM and drawings are at, when they get the design material after the contract is signed. Because of this, in some project the design manager from the contractor must start the design from scratch and in other projects the design manager uses the delivered material, however uncertainty of the maturity and reliability in the previous BIM. The interviewees point out that this could be improved if all the actors in the AEC Industry used MMI on regular basis.

The last challenge that is pointed out, is the use of MMI on an object level, such as in LoD. The interviewed VDC responsible said that if MMI should be implemented on object level in BIM for each object, this will take so much time that it must be specified in the contract with the designers. Other interviewees also argued for the implementation of MMI at object level will not bring any value to the design process, only extra work.

\section{IMPLEMENTING MODEL MATURITY INDEX}

\section{Start - up}

The importance of a start-up meeting was mentioned by the interviewees as a first step to implement MMI, and they pointed out that the main actors in the design team should be represented. The agenda for the start-up meeting should according to the interviewees be first to create a strategy for the project, defining the project goal and who holds the different roles in the project. Then define the BIM - Use strategy. To set this goal is important to know the design team and their BIM skills. The design manager must evaluate which BIM competence there is in the project. Further, the experience and knowledge about MMI must be evaluated. It is also smart to assess what kind of goal the members of the design team individually have for the project. It is also important to clarify what kind of resources the actors in the design team have available to perform the project.

After deciding the strategy, goals, use of BIM and MMI in the project and the design team har gotten to know each other. As pointed out by the production and process responsible, the design team collaboratively should create the wanted MMI working process for the project. The working process should be customized to each building project, but all the interviewees agreed on that it should be based on the flowsheet from the MMI guidelines presented in figure 1. Discussing the flowsheet collaboratively, will according to interviewees give the team members a common understanding of the working process and ownership of what they are supposed to perform. When the team has agreed on a flowsheet, the next step for the team should be to define the MMI levels for the project. 
The MMI levels can be very general or very specific, the interviewees pointed out that this should depend on the project and the team members.

The next step in the start - up meeting according to interviewees is to start considering the deliveries in the project. It was argued that this can be considered as the main job to take MMI into use. Each actor in the design team should define which design activities they shall perform on each MMI level. This practice will create a delivery plan that gives each actor a work package to perform on each MMI level. An example of this is presented in table 1. When creating this table, it is important to think about what do we need to do in this level, and why do we need this to be done at this level?

Table 1: Example of what a delivery plan can look like, this can for example also have a second division under each actor with each building part such as foundation, structure, facade and inner work

\begin{tabular}{|l|l|l|l|l|l|l|}
\hline MMI & Contractor & Architect & $\begin{array}{l}\text { Structural } \\
\text { E. }\end{array}$ & $\begin{array}{l}\text { Electrical } \\
\text { E. }\end{array}$ & $\begin{array}{l}\text { Plumbing } \\
\text { E. }\end{array}$ & $\begin{array}{l}\text { Mechanical } \\
\text { E. }\end{array}$ \\
\hline 100 & & & & & & \\
\hline 200 & & & & & & \\
\hline 300 & & & & & & \\
\hline 350 & & & & & & \\
\hline 400 & & & & & & \\
\hline 500 & & & & & & \\
\hline
\end{tabular}

\section{Planning the design process}

After the start- up meeting it is time to create the design process plan. First, it must be clarified which dependencies there is between the different actors in the process of reaching the MMI levels. This should be done by using a Last Planner System ${ }^{\mathrm{TM}}$ tool for example in a post-it-note session. The post-it-note session makes a visual representation of the design plan and the dependencies, it is easy to understand, and the plan can hang on the wall, so all the team members gets reminded of the plan each time they go into the meeting room.

The plan should be made by creating design milestones for the model. The milestones should represent an MMI level. When creating this design plan, it is important that the plan relates to the production plan, so that the design team reach MMI 400 in time for the production to start as planned. A post - it - note plan can turn out to be quite big, so there could be enough to just put the most important design milestones in the plan and create a separate plan for all deliveries in the design process in some sort data program, such as Excel or MS Project.

Based on Lean thinking it is important to update the plan as the BIM develops. The BIM will develop in different places for each actor, but also for different parts of the building. The production team divides the building into smaller pieces for planning the production phase, in planning the design process the same pieces as in production should be used. These pieces could be divided in both zones and systems. This should be defined for each project, but in general a zone could be a floor, a room or a function inside a building, a system will be such as a HVAC system that goes through multiple zones. 
Planning by using the same zones and systems as the production will ensure that the production drawings will be finished at the right time.

Table 2: Example of how a post - it - note plan can be formed

\begin{tabular}{|c|c|c|c|c|c|c|c|c|c|c|c|c|c|c|}
\hline $\begin{array}{l}\text { Week } \\
\text { number }\end{array}$ & 10 & 11 & 12 & 13 & 14 & 15 & 16 & 17 & 18 & 19 & 20 & 21 & 22 & 23 \\
\hline Milestones & & & & & & & & & & $\begin{array}{l}\text { MMI } \\
300 \\
\end{array}$ & & $\begin{array}{l}\text { MMI } \\
350 \\
\end{array}$ & & \\
\hline Contractor & & & & & & & & & & & & $\begin{array}{l}\text { MMI } \\
350\end{array}$ & & \\
\hline Architect & & & & & & & & $\begin{array}{l}\text { MMI } \\
300\end{array}$ & & & & & & \\
\hline $\begin{array}{l}\text { Structural } \\
\text { E. }\end{array}$ & & & & & & & $\begin{array}{l}\text { MMI } \\
300\end{array}$ & & & & & $\begin{array}{l}\text { MMI } \\
350\end{array}$ & & \\
\hline $\begin{array}{l}\text { Mechanical } \\
\text { E. }\end{array}$ & & & & & & & & & & $\begin{array}{l}\text { MMI } \\
300 \\
\end{array}$ & & $\begin{array}{l}\text { MMI } \\
350\end{array}$ & & \\
\hline $\begin{array}{l}\text { Electrical } \\
\text { E }\end{array}$ & & & & & & & & & $\begin{array}{l}\text { MMI } \\
300\end{array}$ & & & $\begin{array}{l}\text { MMI } \\
350 \\
\end{array}$ & & \\
\hline $\begin{array}{l}\text { Plumbing } \\
\text { E. }\end{array}$ & & & & & & & & & $\begin{array}{l}\text { MMI } \\
300\end{array}$ & & & $\begin{array}{l}\text { MMI } \\
350 \\
\end{array}$ & & \\
\hline
\end{tabular}

\section{Control, measure and evaluation}

The interviewees pointed out that there should be performed a control of the performed work, before an actor can move to next MMI level. Some interviewees pointed out that they use a control form that the design actors must deliver to the design manager for approval. If the performed work is satisfying according to what's expected in the MMI level, the design manager signs the scheme and the actor can continue to develop to model.

One design manager presented a way of controlling all deliveries in real time, where the delivered files gets tagged with the representing MMI level. In this way they always track the development, and they have a diagram that is updated automatically which shows the models MMI level. The design manager says that this gives a clear picture over the model maturity and because all files are tagged with an MMI-level, all participants at a project knows if the design material is finished and ready for use.

Some interviewees also played with the idea of using an automatic control in Solibri, using pre-defined rules. For this to work all objects must be marked with the MMI level in their original model. It is commented that with today's data programs the use of MMI on object level will not provide any value for the project.

\section{DISCUSSION AND CONCLUSION}

Today, very few actors use MMI in Norway. This may be due to uncertainty regarding use and implementation of MMI. Based on the findings from the theory and interviews, a framework is proposed in figure 2. The framework illustrates a way for implementing MMI in an AEC project and a way to structure the model maturity work in the design process. The framework is divided into three main stages, based on the framework made by Knotten 
(2018). The use of the assessment and initialization stage will ensure that the project stakeholders know the project goals, client requirements, and plan and organize the projected based on this. The suggested assessments and initialization in these two stages, will make it easier to utilize the use of BIM, because it is created a common communication language, which is customized to the specific project and the actors of the project. The actor's knowledge and competence regarding the use of BIM, will influence how the MMI language is developed and used.

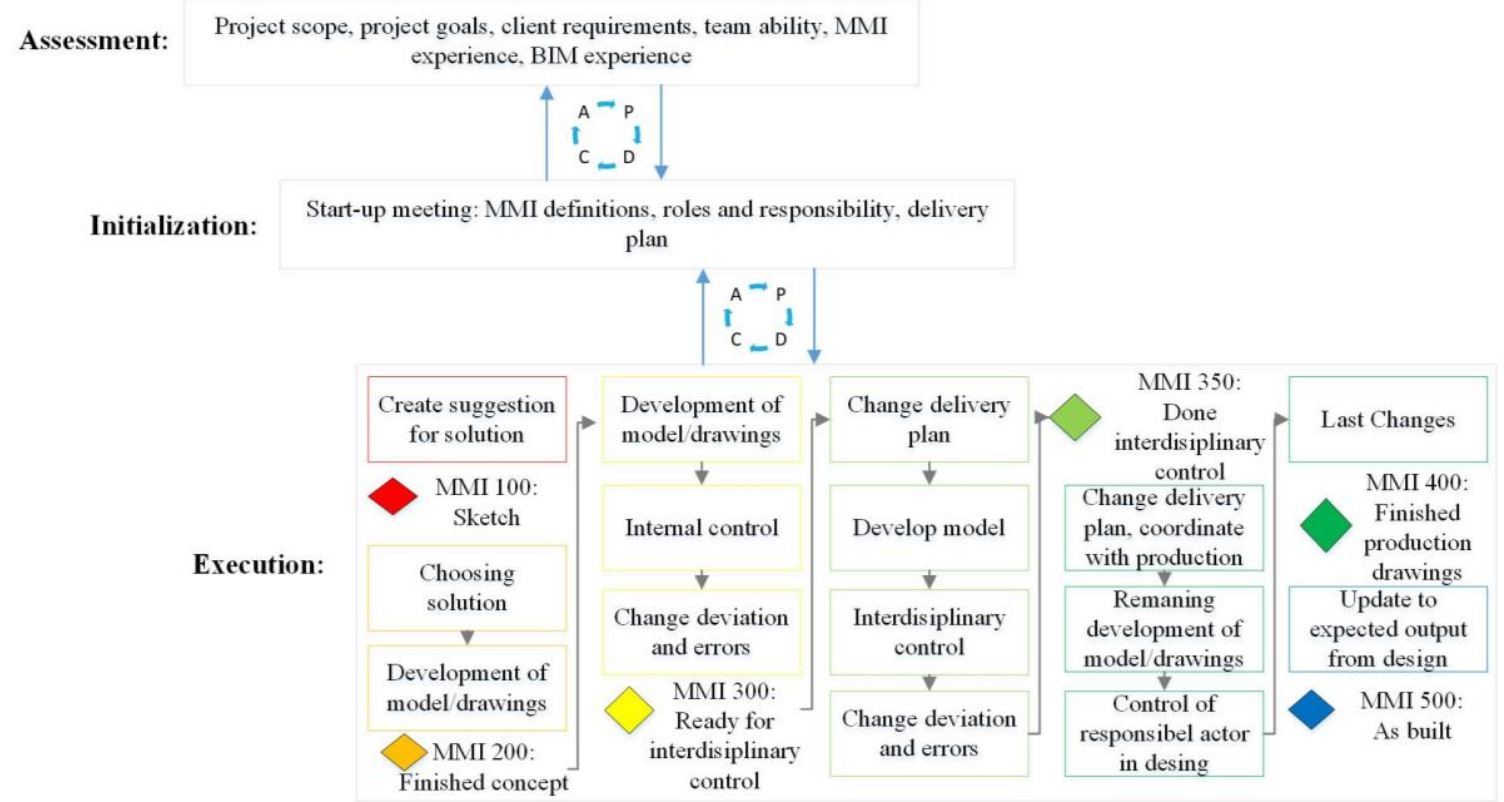

Figure 2: Framework for implementing MMI in a Norwegian building project

Both the initialization and execution stage must be evaluated against the decisions made in stage before. This is illustrated with an PDCA cycle between the stages. The PDCA cycle, also known as Demings cycle, consists of Planning - doing - checking - and acting. The planning is performed in the stage, and then the plans are executed. After or during the execution, there should be performed some sort of check or control. This will ensure that the project is reaching its goal and developing according to the plan made in the previous stage.

The flowsheet in the execution stage is based on the presented flowsheet in figure 1 and findings from interviews, and is developed with inspiration from a framework for the use of LoD created by Hooper (2015). The flowsheet presents activities that needs to be addressed in order to achieve the next MMI. The execution stage focuses on controlling and correcting (Act) the planning and doing of the previous stages. Figure 2 shows which controls should be performed at each MMI level, and that any deviations and errors that occurs must be corrected before the design team can reach the next MMI level. To reach a new MMI level, a BIM - coordinator or the design manager should approve that the expected work in the MMI level is performed and approved. After getting the approval of reaching a new MMI level, the design team can continue with developing the BIM according to the work packages decided for that specific MMI level. This working method 
will ensure continuous improvement, because a control between each level will make problems clear and there will be possible to correct errors before they are passed on. A control will also align the design progress in the BIM with the plan, and the delivery plan can be updated if necessary. This will support a leaner design-process, by removing unnecessary iterations and errors.

The framework with the flowsheet can be used in all contract forms and it doesn't matter which actor brings MMI into the project. It is a huge advantage if MMI gets implemented as soon as possible in the project, to ensure that the design members get an ownership to the working method and communication language. It can be argued that the development from MMI 0 to MMI 200 is missing some details in the flowsheet. The reason for this is that the guidelines created by Fløisbonn et al. (2018) is based on a need from the contractors in the detailed design phase. Therefore, it needs research into the early stages of design. Defining MMI in more detail up to MMI 200, will create a more structured process and give the design team better guidelines to work by.

This research is conducted in the Norwegian AEC Industry and based on Norwegian guidelines; however, the authors believe that the framework and flowsheet is applicable for international AEC projects as well. The framework is generic and needs to be incorporated in the project strategy, and the focus is the improvement of the design process. The design process is almost the same in all countries, as it is almost the same in all contract forms. Using this framework together with LoD will work just as well, because the main point is to improve the design process and not the graphical detail level in the BIM.

\section{REFRENCES}

Abou-Ibrahim, H., and Hamzeh, F. (2016). "Enabling lean design management: An LOD based framework." Lean Construction Journal, 2016, 12-24.

Abou-Ibrahim, H., and Hamzeh, F. "Design Management: Metrics and Visual Tools." Proc., 25th Annual Conference of the International Group for Lean ConstructionHeraklion, Greece, 465-473.

Arayici, Y., Coates, P., Koskela, L., Kagioglou, M., Usher, C., and O'Reilly, K. (2011). "Technology adoption in the BIM implementation for lean architectural practice." Automation in Construction, 20(2), 189-195.

Arksey, H., and O'Malley, L. (2005). "Scoping studies: Towards a methodological framework." International Journal of Social Research Methodology: Theory and Practice, 8(1), 19-32.

BIMForum (2018). "Level of Development (LOD) Specification Part 1 and Commentary." Bølviken, T., Gullbrekken, B., and Nyseth, K. "Collaborative design management." Proc., Challenging Lean Construction Thinking: What Do We Think and What Do We Know? - 18th Annual Conference of the International Group for Lean Construction, IGLC 18, 103-112.

Corbin, J. M., and Strauss, A. L. (2008). Basics of qualitative research: techniques and procedures for developing grounded theory, Sage, Thousand Oaks, Calif. 
El Reifi, M. H., Emmitt, S., and Ruikar, K. "Developing a conceptual lean briefing process model for lean design management." Proc., 21st Annual Conference of the International Group for Lean Construction 2013, IGLC 2013, 325-334.

El. Reifi, M. H., and Emmitt, S. (2013). "Perceptions of lean design management." Architectural Engineering and Design Management, 9(3), 195-208.

Emmitt, S., Sander, D., and Christoffersen, A. K. "Implementing value through lean design management." Proc., IGLC.

Fløisbonn, H. W., Skeie, G., Uppstad, B., Markussen, B., and Sunesen, S. (2018). "MMI Modell Modenhets Indeks." <http://eba.no/globalassets/dokumenter/mmiutvalget/mmi-modell-modenhets-indeks.pdf>. (14.11, 2018).

Fosse, R., Ballard, G., and Fischer, M. "Virtual design and construction: Aligning BIM and lean in practice." Proc., IGLC 2017 - Proceedings of the 25th Annual Conference of the International Group for Lean Construction, 499-506.

Garcia, G., Golparvar-Fard, M., De La Garza, J. M., and Fischer, M. "Model maturity risk index framework for tracking progress in model-based engineering." Proc., Construction Research Congress 2018: Construction Project Management Selected Papers from the Construction Research Congress 2018, $42-52$.

Hamzeh, F. R., Ballard, G., and Tommelein, I. D. "Is the Last Planner System applicable to design? A case study." Proc., 17th Annual Conference of the International Group for Lean Construction, IGLC17, July 13, 2009 - July 19, 2009, National Pingtung University of Science and Technology, 165-176.

Hooper, M. (2015). "Automated model progression scheduling using level of development." Construction Innovation, 15(4), 428-448.

Knotten, V. (2018). "Building design management in the early stages." Degree of Philosophiae Doctor, NTNU, Trondheim.

Knotten, V., Hansen, G. K., Svalestuen, F., and Lædre, O. "Learning across disciplines Use of the Constant Comparative Method." Proc., Proceedings of the 9th Nordic Conference on Construction Economics and Organizations, 273-284.

Leite, F., Akcamete, A., Akinci, B., Atasoy, G., and Kiziltas, S. (2011). "Analysis of modeling effort and impact of different levels of detail in building information models." Automation in Construction, 20(5), 601-609.

Nøklebye, A., Svalestuen, F., Fosse, R., and Lædre, O. "Enabling lean design with management of model maturity." Proc., IGLC 2018 - Proceedings of the 26th Annual Conference of the International Group for Lean Construction: Evolving Lean Construction Towards Mature Production Management Across Cultures and Frontiers, 79-89.

Sacks, R., Koskela, L., Dave, B. A., and Owen, R. (2010a). "Interaction of lean and building information modeling in construction." Journal of construction engineering

management, 136(9), 968-980.

Svalestuen, F., Knotten, V., Lædre, O., and Lohne, J. (2018). Planning the Building Design Process According to Level of Development. 
Styrvold, M., Knotten, V., and Ladre, $O$.

Tauriainen, M., Marttinen, P., Dave, B., and Koskela, L. (2016). "The Effects of BIM and Lean Construction on Design Management Practices." Procedia Engineering, 164, 567-574.

Wohlin, C. "Guidelines for snowballing in systematic literature studies and a replication in software engineering." Proc., ACM International Conference Proceeding Series. 